\title{
TRÊS CONCEITOS-CHAVE PARA A COMPREENSÃO DA SOCIOLOGIA DO DIREITO DE NIKLAS LUHMANN*
}

\author{
Fernando Tonet** \\ Matheus Figueiredo Nunes de Souza***
}

\begin{tabular}{l|l}
\hline RECEBIDO EM: & 19.10 .2020 \\
\hline APROVADO EM: & $1^{\circ} .12 .2020$ \\
\hline
\end{tabular}

* Os autores agradecem a Wálber Araújo Carneiro pelas importantes contribuições para a melhor estruturação do presente trabalho, bem como aos pareceristas anônimos pelas críticas construtivas e revisões.

** Doutor em Direito, com estágio pós-doutoral, pela Universidade do Vale do Rio dos Sinos (Unisinos). Membro do Conselho de Administração da Bruning Tecnometal. Advogado. Desenvolve suas pesquisas nas seguintes áreas: direito constitucional, sociologia jurídica, teoria dos sistemas autopoiéticos e direito criminal. E-mail: fernando.tonet@hotmail.com

*** Mestre em Direito pela Faculdade Meridional (Imed), com bolsa do Programa de Suporte à Pós-Graduação de Instituições de Ensino Particulares (Prosup) da Coordenação de Aperfeiçoamento de Pessoal de Nível Superior (Capes). Professor, com dedicação exclusiva, da Escola de Direito da Faculdade de Balsas (Unibalsas). Membro do grupo de pesquisa Ética, Cidadania e Sustentabilidade, e da Rede Law and Social System. Desenvolve suas pesquisas nas seguintes áreas: teoria dos sistemas autopoiéticos, sociologia das constituições e direito e sustentabilidade. E-mail: matheus.nunnes13@gmail.com 
- RESUMO: O presente artigo apresenta três conceitos-chave para a compreensão da sociologia do direito de Niklas Luhmann: diferenciação funcional, positividade (do direito) e expectativas. O objetivo é conceituar e explicar o que é diferenciação funcional, positividade (do direito) e expectativas, para então, por meio disso, descomplexificar os problemas inerentes à linguagem da teoria dos sistemas. Pretende-se aqui responder à seguinte questão: “Como tornar acessível a teoria dos sistemas, ante sua linguagem complexa, para acadêmicos que nunca tiveram contato anterior com ela?”. O método científico utilizado foi o funcionalista, e empregaram-se os seguintes procedimentos instrumentais: revisão de literatura e categorias e conceitos operacionais. O principal resultado observado é a listagem e explicação, de forma pontual, de conceitos-chave do pensamento jus-sociológico luhmanniano, mas que também podem ser utilizados pelo acadêmico para seguir em outros escritos. Destaca-se, no entanto, que o presente estudo é limitado à sociologia do direito de Luhmann, portanto, anterior à chamada "virada autopoiética".

PALAVRAS-chave: Diferenciação funcional; direito positivo; expectativas cognitivas e normativas.

\section{THREE KEY CONCEPTS FOR UNDERSTANDING} NIKLAS LUHMANN'S SOCIOLOGY OF LAW

- ABSTRACt: The article presents three key concepts for understanding Niklas Luhmann's sociology of law: functional differentiation, positivity (of law) and expectations. The objective is to conceptualize and explain what is functional differentiation, positivity and expectations, and then, through this, to decomplex the problems inherent in the language of systems theory. It is intended here to answer the following question: "How to make systems theory accessible, in view of its complex language, for academics who have never had previous contact?". The scientific method used was the functionalist. The instrumental procedures employed were the literature review and categories and operational concepts. The main result observed is the listing and explanation, in a punctual way, of key concepts of luhmannian jus-sociological thinking, but which can also be used by the academic to follow in other writings. It is noteworthy, however, that the 
present study is limited to Luhmann's sociology of law, therefore, prior to the socalled "autopoietic turn".

- keywords: Functional differentiation; positive law; cognitive and normative expectations.

\section{Introdução}

O presente trabalho aborda a sociologia do direito de Niklas Luhmann e três conceitos-chave para a compreensão dela, quais sejam: diferenciação funcional, positividade (do direito) e expectativas. A seleção dessas categorias se deve à contribuição para o entendimento da sociedade moderna e ao surgimento de subsistemas especializados, principalmente o sistema jurídico.

A ideia originou-se a partir das aulas de Ciência Política e Teoria Geral do Estado para alunos do primeiro semestre do curso de Direito, em que se buscava, ao longo da disciplina, explicar a correlação entre evolução social e surgimento do direito como sistema, desde as sociedade arcaicas até os problemas decorrentes da globalização. Como se tratava de discentes que haviam ingressado recentemente no ensino superior e, portanto, não tiveram contato com teorias densas, como a teoria dos sistemas, era necessário explicar conceitos complexos de forma simples (mas não simplória). Não obstante isso, acadêmicos de diferentes níveis deixam de se aprofundar nessa vertente teórica, haja vista os problemas e a complexidade de uma linguagem própria à teoria (LUHMANN, 2002).

Dessa maneira, a presente pesquisa se justifica como mecanismo para redução da complexidade para a necessária compreensão da teoria de base apresentada. Muito embora a construção teórica que move este texto revise a literatura científica existente, sua relevância repousa em como o conteúdo é trazido: diversas obras introdutórias (livros, artigos...) à teoria dos sistemas utilizam da própria complexidade do arcabouço semântico para expor o conteúdo, o que obriga o leitor a dominar, minimamente, algumas conceituações antes de aprofundar os estudos; e de forma contrária, a presente proposta procura permitir que o leitor que não teve nenhum contato prévio com a sociologia do direito de Niklas Luhmann possa, por meio de uma linguagem mais simples, apreender essas ideias fundamentais, de maneira que possa seguir para leituras mais complexas. 
O objetivo deste texto é conceituar e explicar o que é diferenciação funcional, positividade (do direito) e expectativas, para então, por meio disso, descomplexificar os problemas inerentes à linguagem da teoria. O problema de pesquisa de que se parte é o seguinte:

- Como tornar acessível a teoria dos sistemas, ante sua linguagem complexa, para acadêmicos que nunca tiveram contato com ela?

Para cumprir com o proposto, o método científico utilizado foi o funcionalista, desenvolvendo uma pesquisa qualitativa, essencialmente teórica e descritiva. Os procedimentos instrumentais (técnicas de pesquisa) empregados foram a revisão de literatura, selecionada, respectivamente, pelos critérios de relevância, acessibilidade e atualidade; e categorias e conceitos operacionais.

O texto é divido em três seções, uma para cada conceito-chave a ser explicado. Primeiramente, apresenta-se a matriz teórica sistêmica, identificando o objeto de estudo de Luhmann, qual seja, os sistemas sociais, compostos pelo elemento básico comunicação. Explica-se, então, que a sociedade compreendida como sistema de comunicações apresenta limitadas formas de organização social - segmentação, estratificação e diferenciação funcional. Estas, por sua vez, são formas de diferenciação sistêmica, princípios que orientam como as comunicações são organizadas no interior da sociedade (I). Na segunda seção, explica-se o que é positividade do direito, também encontrado dentro da teoria dos sistemas sob a categoria de "fechamento operativo do direito". Aqui se buscou explicar como o direito positivo (funcionalmente diferenciado) se autonomiza, conceituando positividade, e como ele é percebido por meio das dimensões de sentido. Foi necessário introduzir as categorias de código binário e programação, para explicar que, na diferenciação funcional, apenas o sistema jurídico gerencia as questões sobre legal/ilegal atribuídas por normas jurídicas (II). Por último, apresentou-se o que são expectativas: condensações de sentido que são repetidas ao longo do tempo, em um processo de evolução, que buscam orientar a produção das comunicações pelos sistemas sociais. Como nem sempre as expectativas são cumpridas (problema da dupla contingência), desenvolvem-se expectativas sobre expectativas, que nada mais são que as estruturas de um sistema. Ainda, apresentaram-se as formas de lidar com desapontamentos de expectativas (III). 


\section{Diferenciação funcional}

A concepção do que é diferenciação funcional está intrinsecamente ligada à de sociedade, formulada no âmbito da teoria dos sistemas sociais autopoiéticos, haja vista que se trata de um dos princípios de organização social. Dessa maneira, é preciso esclarecer o que é um sistema e como a sociedade pode ser compreendida como tal, para só então se ater, especificamente, à sua organização interna.

O paradigma sistêmico é heterogêneo, perpassando desde a noção de sistema aberto, em constante troca de energia com o ambiente, até a remissão ao todo e às (a soma das) partes. No entanto, tais construções teóricas não estão aptas a lidar com a (hiper)complexidade contemporânea, razão pela qual se recorre às formulações de Niklas Luhmann, que afirma que um sistema é um número, mais ou menos grande, de diferenças entre sistema/ambiente (System/Umwelt) que são operativamente utilizáveis, cada uma das quais reconstrói o sistema total como unidade de subsistemas e ambiente, em diferentes linhas de intersecção (LUHMANN, 1991, p. 22; 2016a, p. 23).

Empiricamente, a realidade é experimentada como a própria reprodução dessas operações que produzem diferenças. Assim sendo, é possível distinguir quatro grandes categorias de sistemas: máquinas, organismos, sistemas psíquicos e sistemas sociais. O primeiro é formado por uma série de elementos que não são auto-organizados, necessitando de intervenções externas para seu funcionamento. Organismos são formas que se produzem a partir de si mesmas (autopoiéticas) geradas por processos biológicos, físicos e químicos, fechados no nível de suas operações - é a forma de organização dos vivos (MATURANA; VARELA, 2003).

Os sistemas psíquicos e sociais também se autoproduzem, isto é, são autopoiéticos: fechados no nível de suas operações, mas, por serem formas de sentido, são abertos cognitivamente. A consciência é formada pela (re)produção de pensamentos, e os sistemas sociais são constituídos pela recursividade da comunicação.

Diante da contraposição da sociedade como um tipo de sistema social e a tradição veteroeuropeia humanista, questionar-se-ia: como é possível haver uma sociedade sem pessoas?(IZUZQUIZA, 2008). De pronto, a resposta dada por Niklas Luhmann (1997, p. 76) é: “ela é composta de braços e pernas, pensamentos e enzimas?” (cf. RODRIGUES; NEVES, 2017, p. 87) ${ }^{1}$.

1 Uma das grandes críticas atribuídas à teoria dos sistemas é que, ao elaborar um conceito de sociedade radicalmente anti-humanista, anti-regionalista e construtivista (LUHMANN, 2006, p. 20), ela passaria então a ignorar o ser 
É justamente pela complexidade do ser humano como entidade concreta, empiricamente formada química, física, psicológica e organicamente, que não se pode concebê-lo como elemento da sociedade. Existe a necessidade de um tipo diferenciado de elemento que sirva à base operativa dos sistemas sociais, e tal é a comunicação².

Assim, tomando a teoria dos sistemas como teoria da sociedade, tudo que é comunicado ou é sociedade ou faz parte da sociedade (ROCHA; SCHWARTZ; CLAM, 2013, p. 63). Trata-se do sistema omniabarcador que contém todas as comunicações.

Deixando isso delineado, é possível identificar apenas um número limitado de formas de organização social, a saber: segmentação, estratificação e diferenciação funcional.

Quando se fala em segmentação, está-se voltando para sociedades arcaicas, que são orientadas para a formação diferenciada de subsistemas igualitários - igualdade, aqui, se refere aos princípios autosseletivos da formação sistêmica. Esses critérios orientadores da seletividade são a "origem étnica”, o lugar onde se vive, ou, ainda, a combinação de ambos. Já por estratificação se compreende uma formação diferenciada de subsistemas desiguais, característicos das civilizações pré-modernas. A igualdade/ desigualdade aqui está associada à distinção sistema/ambiente, em que igualdade é a regra para a comunicação interna, enquanto a desigualdade é a regra para a comunicação para o entorno (LUHMANN, 1977, p. 32; 1998, p. 76).

Por último, com a ascensão da diferenciação funcional, os processos comunicativos passam a ser organizados em torno de funções específicas e interdependentes, sem que haja uma primazia funcional de um dos subsistemas no nível da sociedade. Para tanto, há uma institucionalização por essas estruturas para resolver problemas sociais específicos, bem como promover um novo set de relações entre sistema e entorno. A política, por exemplo, é o subsistema social responsável pela produção de decisões coletivamente vinculantes; a religião busca interpretar o incompreensível; o direito deve, consistentemente, generalizar expectativas normativas (LUHMANN, 1977, 1990a, 1993a, 1998, 2006).

humano como elemento principal da sociedade. Nesse sentido, destaca-se que tais críticas não têm fundamento, pois se baseiam naquilo que o sociólogo alemão chamava de velho pensamento europeu, de maneira que o mundo "nunca foi exclusivamente humano, e a sociedade não está presa às limitações do homem" (SCHWARTZ, 2014, p. 112). Em seu Sistemas Sociais, Luhmann (2016a, p. 80) já havia enfrentado essa questão ao afirmar que as pessoas estão no ambiente da sociedade, porém, são fundamentais para a própria observação da sociedade, de maneira que um não pode existir sem o outro, pois surgem e coexistem por coevolução.

2 "La comunicación también es genuinamente social porque de ningún modo y en ningún sentido puede producirse una consciencia 'común' colectiva: la comunicación funciona sin que pueda llegarse al consenso en el pleno sentido de acuerdo verdaderamente completo. La comunicación es la unidad más pequeña posible de un sistema social [...]” (LUHMANN, 2006, p. 58). 
Dito isso, é possivel afirmar que estratificação, segmentação e diferenciação funcional são formas de diferenciação sistêmica, ou seja, são princípios de organização dos processos comunicativos no interior da sociedade. Por sua vez, diferenciação sistêmica énada mais que uma construção reflexiva do sistema para fins de amplificação dos próprios resultados: uma técnica de duplicação da distinção sistema/ambiente dentro do próprio sistema para melhor manejo da complexidade interna.

- FIGURA 1 - DIFERENCIAÇÃo SISTÊMICA

AMBIENTE(EXTERNO)

\section{AMBIENTE(EXTERNO)}

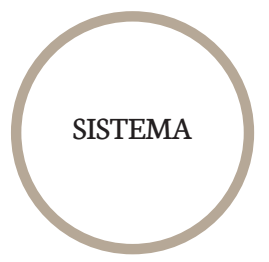

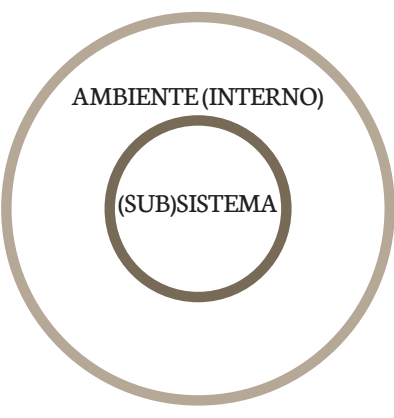

FONTE: ELABORADA PELOS AUTORES.

Para que tal concepção seja mais facilmente percebida, pode-se dizer, com Stichweh (2020), que diferenciação significa a distribuição de atividades sociais e de participantes da sociedade entre subsistemas (nos quais a sociedade consiste).

As primeiras sociedades, surgidas há milhares de anos, eram formadas por caçadores/coletores, consistindo em algumas dezenas ou, no máximo, algumas centenas de membros. Eram marcadas por serem móveis, migratórias, que se deslocavam quando os recursos nutritivos já não eram suficientes para suprir suas necessidades (STICHWEH, 2018, p. 390).

Falar em sociedade segmentariamente diferenciada, assim, significa que se está diante de uma organização social baseada no território e/ou na etnia de grupos, tribos ou famílias, que se mantêm coesas a partir da ascendência e da história comum. As relações sociais são fundamentadas no parentesco. Por causa da baixa complexidade e abstração, as formas de responder aos problemas sociais são heterogêneas, desenvolvendo-se instituições concretamente. Ao tomar como exemplo o direito, essas instituições 
são criadas na frustração e na reação do frustrado, nos conflitos, não sendo possível ignorar quem são os envolvidos, direta ou indiretamente, e quais as referências aos antepassados, às propriedades ou aos prestígios (LUHMANN, 1983, p. 184-188).

FIGURA 2 - SOCIEDADE SEGMENTÁRIA

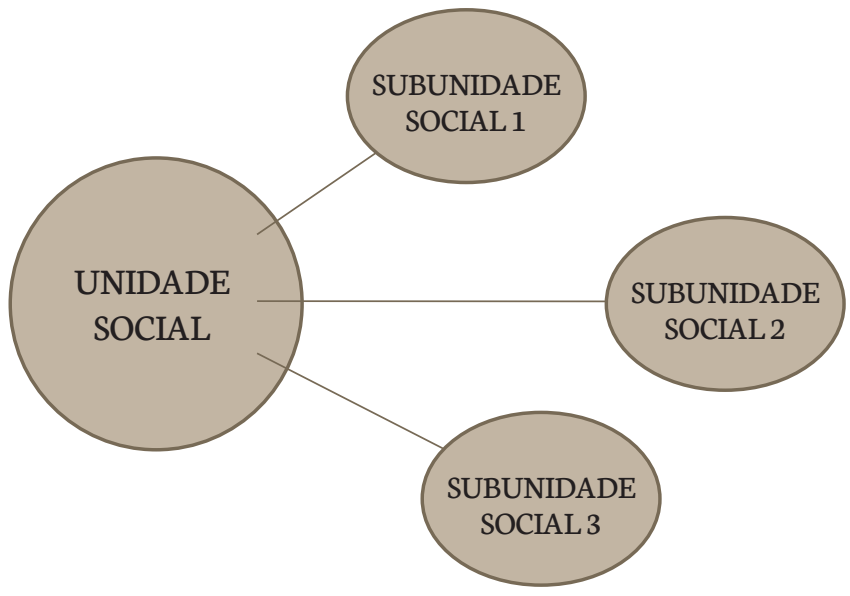

FONTE: ELABORADA PELOS AUTORES.

Diferenciação segmentária nada mais é que esse processo de surgimento de subunidades sociais: quando a sociedade arcaica se torna muito complexa, ela cria novas (sub)unidades que existirão com uma ligação de ascendência, uma história comum e relações sociais fundamentadas no parentesco.

Com a evolução social, por meio de um proeminente desenvolvimento econômico (formação de cidades e construção e administração de sistemas de irrigação) e um processo de separação de dominação política dos graus de parentesco, há uma complexificação dos sistemas sociais, mudando a forma de organização, de maneira que as sociedades pré-modernas agora se orientam a partir de estratos. Passa-se à agregação de instituições religiosas e políticas. Nesse contexto, surge a figura do Estado (soberano) como símbolo da unificação entre direito e política, que conta com uma estrutura hierárquica a partir de grupos (nobreza, clero, plebeus, camponeses) verticalmente dispostos. A inclusão dos indivíduos na sociedade ocorre pelo nascimento em um dos estratos e a exclusão é apenas pela morte, não havendo, portanto, nenhuma perspectiva de mobilidade social (um camponês ascender à nobreza, por exemplo). 
É possível descrever essa sociedade como uma estrutura assimétrica de comunicação, com fixação de papéis e divisão de tarefas correspondente ao estrato em que o indivíduo nasce. Há uma generalização diferenciada de prestígio entre "superior" e "inferior" - ou seja, aquelas figuras proeminentes devem se apoiar nas proeminências: quem manda politicamente também é o mais rico, o mais sábio, de linhagem notável, quem detém o comando militar, quem detém o maior número de servos, entre outros (LUHMANN, 1983, p. 205-206).

Para o direito, passa-se a procedimentos de aplicação jurídica que são institucionalizados e caracterizados por uma incerteza do resultado. No entanto, a atividade aplicadora dos juízes é orientada por normas e princípios abstratos, compreendidos como imutáveis (distinção direito natural/direito positivo), e o direito, concebido como algo verdadeiro (NEVES, 2012, p. 21-22).

- FIGURA $3 \cdot$ SOCIEDADE ESTRATIFICADA

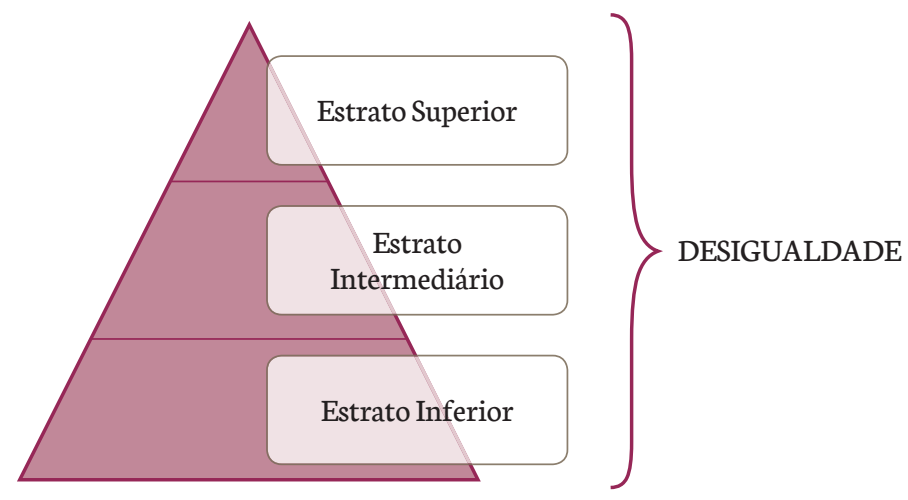

FONTE: ELABORADA PELOS AUTORES.

Estados hierarquicamente estruturados existiram na Europa pré-moderna até o final do século XVII e a primeira metade do século XVIII. A partir de 1750, a efervescência dos contextos revolucionários francês e norte-americano muda completamente a forma de organização interna da sociedade: as estruturas (sistemas) se tornam autônomas e se especializam, desempenhando funções determinadas para resolver problemas sociais específicos e organizando os processos comunicativos em torno dessas.

No nível dos sistemas sociais, isso significa que quem governa politicamente não se ancora mais nas proeminências, no apoio da nobreza e do clero e do controle do 
poder militar, mas sim na soberania do povo; e o direito deixa de ter fundamentos de validade metafísicos, externos a si (Deus, Natureza, Razão, entre outros), e passa a ser baseado em uma constituição ${ }^{3}$. Isso gera um sem-número de descrições da própria sociedade que impossibilita a representação da sua unidade por um só sistema (por exemplo, como societas civilis, pela política, nas sociedades pré-modernas).

A diferenciação funcional transfere atividades de pessoas que nasceram para exercê-las para experts e profissionais: a especialidade sobre as normas passa do monarca como juiz aos experts jurídicos; o monarca e a nobreza, que deliberavam sobre política, cedem espaço a uma política fundada na soberania do povo, com a instituição de partidos políticos, parlamento e uma administração imunizada; o empreendedorismo que era parte das economias domésticas e a sucessão interna à família dão lugar aos gerentes como especialistas; as universidades conferiam cadeiras a familiares, mas, agora, a pesquisa científica e universitária é tida como carreira profissional.

- FIGURA $4 \cdot$ SOCIEDADE FUNCIONALMENTE DIFERENCIADA

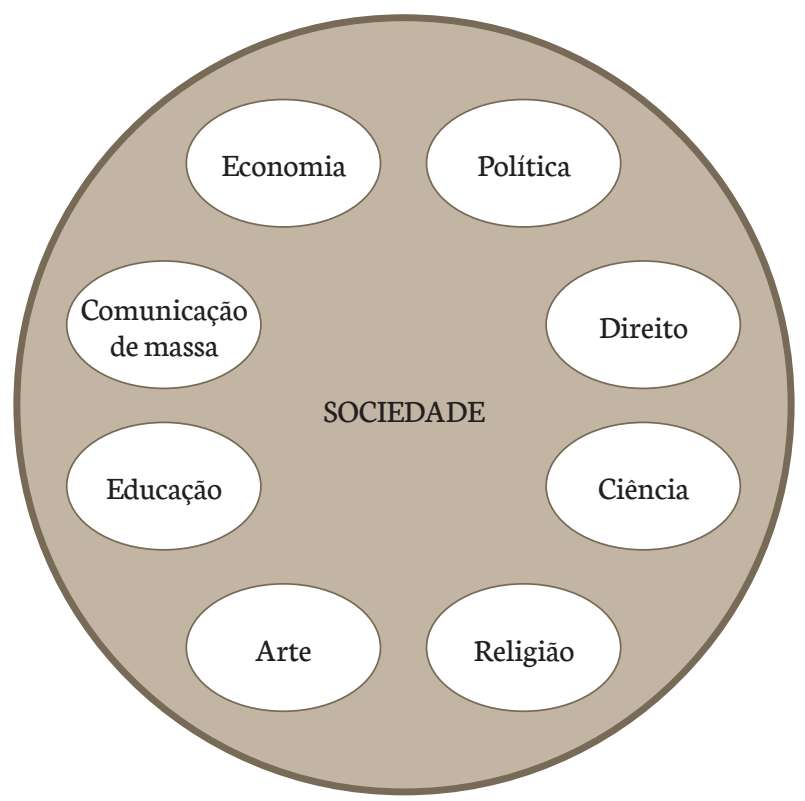

FONTE: ELABORADA PELOS AUTORES.

3 Na jurisprudence, o termo constitutio é utilizado em referência a decretos de direito positivo que têm força de lei. Observando a partir de uma linguagem política, constitutio(n) é uma constituição corpórea que pode se referir tanto ao homem singular quanto ao corpo político (LUHMANN, 1990b; STOURZH, 2007, p. 84 et seq.). 
Diferenciação funcional é, portanto, um princípio de organização interna dos processos comunicativos de uma sociedade; uma forma de diferenciação sistêmica que organiza a sociedade em subsistemas sociais autônomos, que cumprem funções determinadas na busca da resolução de problemas sociais específicos.

A sociedade funcionalmente diferenciada, que se erige há cerca de 250 anos e perdura até hoje, também é conhecida como sociedade moderna, haja vista que é o último produto da evolução sociocultural. Falar que uma sociedade é moderna significa dizer que a única forma de desigualdade é uma desigualdade de funções ${ }^{4}$ e que as pessoas passam a ser incluídas socialmente à comunicação por meio dos papéis especializados que desempenham, podendo agir em diferentes sistemas.

\section{Positividade do direito}

Este tópico comumente tratado na literatura da teoria do direito é trabalhado pela teoria dos sistemas sob a classificação de "fechamento operativo do direito".

Com a separação estrutural entre política e direito a partir dos contextos das revoluções americana e francesa, a sociedade adquire evolutivamente uma estrutura que passa a interligar esses dois sistemas: a Constituição. Com ela, as bases que haviam sido postuladas pelo jusnaturalismo são destronadas, substituindo o direito natural em sua visão cosmológica ou o direito racional no seu viés transcendental. A antiga intangibilidade do direito passa a ser substituída pela lei constitucional - ou seja, expulsa-se toda justificação externa (Deus, Natureza, Razão...) -, e a fundamentação da juridicidade passa a ser na própria ordem constitucional.

Isso significa o surgimento de um Estado de Direito que implica a subordinação das decisões políticas ao direito, ao mesmo tempo que a produção jurídica não pode renunciar a uma legislação que foi deliberada politicamente (NEVES, 2012, p. 89-90). No entanto, não se deve confundir a instauração de processos legislativos, que é componente institucional da vida político-estatal, com o próprio direito positivo. Não se trata de um ordenamento jurídico posto por um ato de vontade de uma autoridade (Kelsen).

\footnotetext{
4 Sobre os problemas de desigualdade e exclusão social, cumpre destacar o posicionamento tardio de Niklas Luhmann (1993b, p. 585-586; 1995; 2006; 2016b, p. 106, 642). Já sobre as limitações da concepção de diferenciação funcional na recepção brasileira da teoria dos sistemas, ver Neves (2012, 2018), Dutra (2014, 2016, 2020) e Souza e Tonet (2018).
} 
Só se pode falar em positividade quando o direito se estabelece como base do próprio direito (LUHMANN, 1983, p. 236): a lembrança de um ato legislativo que aconteceu em determinado período histórico serve de base à vigência de uma decisão como escolha entre diversas possibilidades, que por sua vez pode ser confirmada ou ser declarada ilegal (revogada) por outra decisão, e assim sucessivamente.

Tendo em vista o exposto, propõe-se (1):

$$
D \rightarrow \ldots d_{n}+d_{n+1}+d_{n+2}+d_{n+3} \ldots \rightarrow D
$$

FONTE: ELABORADA PELOS AUTORES.

Em linhas gerais, o conceito de positividade pode ser resumido à formulação de que o direito $(D \rightarrow)$ não apenas é estatuído por meio de decisões $\left(\ldots d_{n}+d_{n+1}+d_{n+2}+d_{n+3} \ldots\right)$, mas adquire sua vigência com referência a essas decisões $(D \rightarrow)$ - quer dizer, torna-se decidível e alterável (LUHMANN, 1985, p. 9-10).

No sentido da proposição (1), o fechamento operativo é alcançado por meio de uma cadeia de decisões que faz referência a outras decisões e que, portanto, pode ser representada como circularidade!

- FIGURA 5 POSITIVIDADE COMO CIRCULARIDADE DO DIREITO (D)

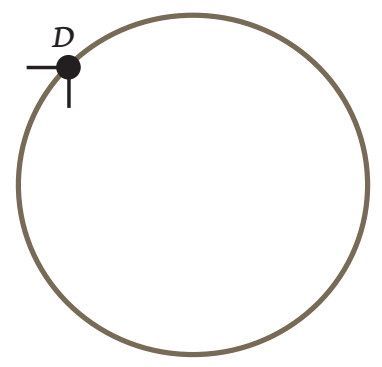

FONTE: ELABORADA PELOS AUTORES.

O direito positivo é experimentado a partir de três vetores que existem simultaneamente, isso significa que é percebido em três dimensões (de sentido) entrelaçadas entre si, a saber: uma temporal, uma material e uma social. 
Temporalmente, a realidade é sempre vivenciada no presente ${ }^{5}$. Acontece uma institucionalização de um direito que pode ser modificável, oferecendo um caráter de dinamicidade estrutural. Em outras palavras, hoje pode viger um direito que não existia, assim como amanhã esse direito pode ser modificado ou até mesmo extinguido (LUHMANN, 1985, p. 10).

Na dimensão material, a função da positividade diz respeito ao conteúdo das normas que estão em vigência: a multiplicidade de temas que são passíveis de tratamento jurídico. Esse vetor deriva da temporalidade: tendo em vista que o "conteúdo" sempre diz respeito a um direito que está em vigência (um direito do presente), não há necessidade de se comprovar que sempre tenha feito parte do direito (LUHMANN, 1985, p. 11).

Por último, quando se refere à dimensão social, o fechamento operativo está associado ao âmbito de aplicação das possibilidades jurídicas, quer dizer, à capacidade de generalização. Um determinado direito vigente (dimensão temporal) possui um determinado tema (dimensão material) e deve ser aplicado ao maior número possível de pessoas diferentes entre si (dimensão social). Está-se tratando, nesse vetor, da necessidade de abstração/indiferença e aceitação do direito (LUHMANN, 1985, p. 12).

Na Figura 6, os autores procuram representar a positividade do direito, conforme descrito anteriormente, nas três dimensões do sentido. Dessa maneira, é possível identificar três eixos: horizontal, vertical e transversal.

- FIGURA 6 P PERCEPÇÃo do DIREITO POSITIVO NAS DIMENSÕES DE SENTIDO

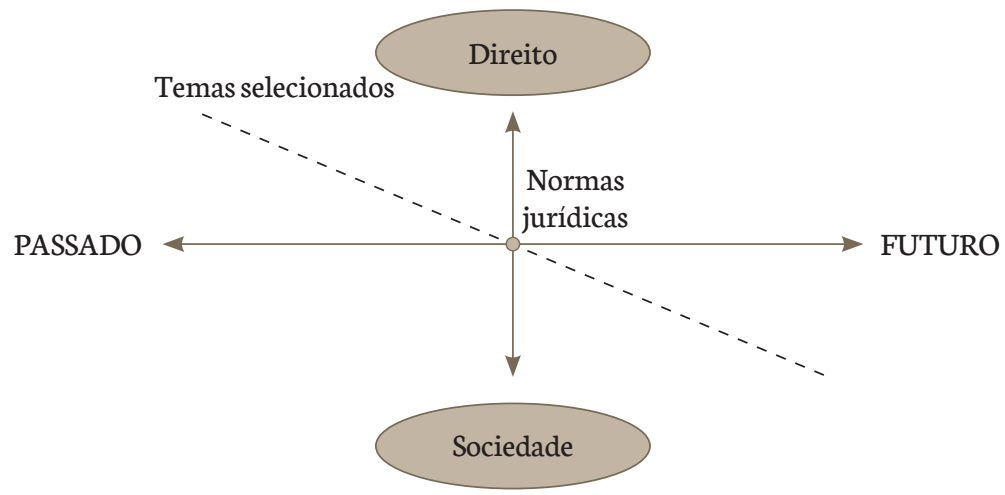

FONTE: ELABORADA PELOS AUTORES.

5 Na teoria dos sistemas, o presente nada mais é que uma distinção entre passado e futuro (um antes e um depois), que é constantemente atualizada e então experimentada imediatamente (agora) (LUHMANN, 2016a, p. 100). 
Horizontalmente se tem a dimensão temporal, a distinção passado/futuro para a positividade do direito que é atualizada a todo momento e vivenciada como presente, ao passo que, na posição vertical, indica-se a dimensão social: da estrutura jurídica específica (o próprio direito como sistema social funcionalmente diferenciado) até a sociedade (sistema abarcador de todas as comunicações), certas expectativas normativas têm pretensão de valerem para todos.

Em ambos os eixos, nas duas extremidades, foi utilizado uma marca gráfica $(\triangleright,>)$, propositalmente, a fim de demonstrar para o leitor que, independentemente para onde se desloque - para frente ou para trás; para cima ou para baixo -, sempre se volta ao ponto do qual se partiu ${ }^{6}$ : uma vigência do direito no presente e com pretensão de abstração e aceitação social.

Já no eixo transversal se indica a dimensão material do sentido, responsável pela seleção de temas que representam o “conteúdo das normas jurídicas”. Aqui, a memória de um ato legislativo (portanto, algo no passado) é fundamental para a reorientação, em termos mundiais, da positividade do direito, que tem a pretensão de se cristalizar no futuro. É importante, especialmente, para o estabelecimento das condições de retidão objetiva da decisão jurídica.

A representação vetorial parte de certo ponto no passado, em direção ao futuro; e do direito, em direção à sociedade. Isso significa que o conteúdo das comunicações jurídicas pode ser variável com o passar do tempo (o direito que vige hoje pode não existir amanhã), mas se busca condensar o sentido daquela comunicação originada em um evento para utilização em momentos posteriores.

\subsection{Código binário e programação}

Muito embora a recursividade das decisões seja importante para compreender o que é a positividade, isto é, o fechamento operativo do direito, ainda não é suficiente, pois, na primeira seção deste manuscrito, apresentou-se que a diferenciação social provoca uma reorientação global dos processos comunicativos em torno de estruturas sociais (subsistemas da sociedade) que exercem funções diferentes na solução de problemas sociais específicos.

6 Essa ideia se alinha com a concepção de hierarquias entrelaçadas (tangled hierarchies) de Hofstadter (2001, p. 751 et seq.). Muito embora se utilize o termo hierarquia, não há uma relação de subordinação de uma dimensão de sentido a outra, mas um relacionamento circular e difuso de diferentes níveis. 
Com o direito moderno não é diferente. Ele é o (sub)sistema social constituído por comunicações jurídicas diferenciadas de outras existentes no entorno (comunicações políticas, econômicas, científicas...), que, desde o direito arcaico, busca resolver o problema da generalização congruente das expectativas normativas. Portanto, é o único sistema que gerencia o código binário direito/não direito (recht/unrecht).

E para arrematar a explicação sobre o que é a positividade do direito, é preciso introduzir as categorias de "código binário" e "programação".

Um código binário é uma estrutura que existe em todos os sistemas sociais e é responsável pela generalização da linguagem utilizada. É caracterizado por três pontos: 1. são construções totalizantes, abrangentes, e não possuem limites ontológicos, em que tudo que cai no seu domínio de relevância é assinalado com um valor ou outro, com a exclusão de terceiros valores; 2 . a totalização leva a uma contingência de todos os fenômenos, sem exceção, ou seja, tudo que aparece como possibilidade do contra valor ou é necessário ou impossível; e 3. códigos são tão distantes quanto abstrações, sendo válidos apenas à medida que a comunicação entra em seu domínio de aplicação. Portanto, sua aplicação é um fenômeno socialmente contingente, tendo em vista que essa é a única maneira de totalizar um esquema que reduza tudo a duas possibilidades opostas (LUHMANN, 1989, p. 38).

O código binário é uma estrutura lógica que reduz toda a complexidade do mundo a dois valores, um positivo e outro negativo. Serve no auxílio do fechamento operativo (positividade) do direito, a fim de distinguir se o tipo de comunicação pertence ou não àquele sistema, muito embora não seja responsável por estabelecer as "regras de aplicação". Os critérios que o sistema utiliza para atribuir a comunicação ao valor positivo (direito) ou negativo (não direito) são definidos pelos programas.

Pode-se dizer que os programas definem as condições de retidão objetiva da decisão (LUHMANN, 2000, p. 205-206), ou seja, constituem regras que são responsáveis pela especificação das suas próprias condições de aplicação. Em linhas sistêmicas, os programas dão as condições de aptidão da seleção de operações (LUHMANN, 1989, p.45).

Existem dois tipos de programa: de fins e condicionais. Nos programas de fins, os efeitos esperados são fixos e a ação que leva a eles não é especificamente indicada, mas qualquer ação é considerada correta, o que implica os efeitos fixados pela regra (são programas característicos de sistemas como a política, a economia, entre outros). Já os programas condicionais são característicos do sistema do direito, pois são responsáveis por fixar certas causas como produtoras de determinados efeitos com um esquema 
que estabelece que, se acontecerem certas condições, então será produzido um efeito determinado (ALCOVER, 1993, p. 218).

O que os programas condicionais fazem é estabelecer as condições que definem se algo é legal ou não. Essas condições fazem referências a fatos passados que podem ser verificados atualmente, sendo decisivo que a atribuição do que é ou não direito dependa daquilo que, no momento da decisão, seja considerado passado - isso quer dizer, o sistema do direito sempre atua a posteriori.

Dessa maneira, toda decisão jurídica, toda norma jurídica, toda comunicação jurídica, em sentido amplo, que opera sucessivamente guiada por critérios objetivos de seleção, indicando o lado interno do código (portanto, o que é direito), afirma e reafirma que a base de produção do direito é ele próprio, e não outro fundamento externo de validade.

\section{Expectativas}

De acordo com o Novo dicionário enciclopédico Webster (1995, p. 352), expectativa (expectation) é o estado de expectar, esperar, um olhar adiante para ou esperar por algo. Dessa maneira, pode-se inferir que ter expectativas é esperar, a partir de uma determinada situação, que algo venha a acontecer: uma pessoa que não conhece a cidade e procura um determinado lugar pede informação a um morador, esperando, assim, a informação desejada.

Não destoando dessa compreensão, no contexto da teoria dos sistemas sociais, expectativas são generalizações simbólicas ${ }^{7}$ que condensam uma estrutura remissiva de todo sentido em expectativas que indicam o que dada situação de sentido promete (LUHMANN, 1991, p. 139; 2016a, p. 119). A função delas é orientar, de forma estável, a comunicação e o pensamento ante a complexidade e a contingência do mundo.

Partindo de três fatores, a saber, a infinita complexidade do mundo, a necessidade de redução dessa complexidade para o funcionamento do sistema e a característica de abertura da comunicação, como operação autorreferencial ${ }^{8}$-, a expectativa pode ser entendida como um mecanismo desenvolvido que permite a reacessibilidade

7 De acordo com Luhmann (1991, p. 137; 2016a, p. 117), o conceito de generalização simbólica da autorreferência do sentido substitui o conceito de signo, que até o momento havia dominado a tradição teórica.

8 A comunicação, como elemento que constitui os sistemas sociais, sempre faz remissão a outras comunicações, sendo uma operação autorreferencial (que faz referência a operações da mesma natureza). Essas operações não absorvem o sentido geral, não têm efeito totalizador, mas apenas seguem, elas não fecham, não conduzem ao fim, não cumprem um télos, mas apenas abrem (LUHMANN, 1991, p. 606; 2016a, p. 507). 
de uma determinada situação e a resposta a ser dada, sem que se tenha de vivenciar todo o processo novamente, ganhando tempo nas operações.

Em se tratando de sistemas sociais, ao se deparar com um problema social novo (uma variação), necessita-se de tempo para processar aquela complexidade e escolher a resposta mais adequada a ser dada (uma seleção), e, por fim, internaliza-se essa resposta como algo incorporado, pertencente, ao próprio sistema (uma estabilização). Porém, em outro momento, quando um problema semelhante se apresenta para o sistema, ele pode utilizar o que já aprendeu para reagir a essa nova variação, não precisando, necessariamente, despender o mesmo tempo da primeira vez.

Ao longo do processo de evolução sociocultural, o sistema repete isso continuamente, condensando, então, um determinado sentido, restringindo o âmbito de relações entre as comunicações admitidas no sistema e então passa à generalização (simbólica) para ser (re)utilizado ulteriormente. Dito de outra forma, essa condensação generaliza o sentido que permite manter a identidade no sistema, independentemente do acontecimento singular - ou da situação única.

Isso acontece com todos os sistemas sociais, levando, assim, a sociedade moderna a enfrentar o problema da chamada dupla contingência.

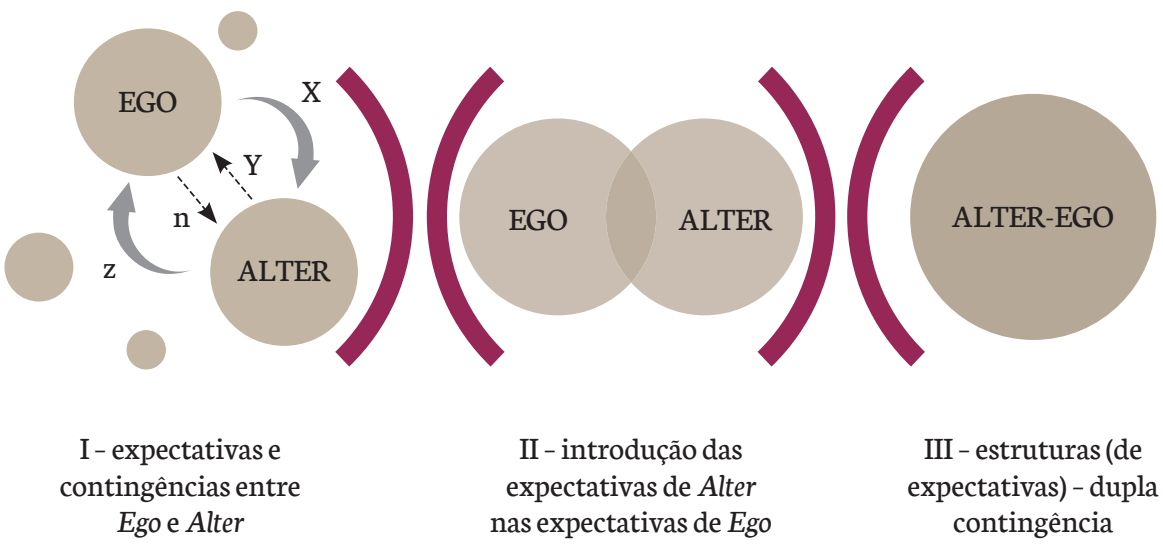

FONTE: ELABORADA PELOS AUTORES.

A dupla contingência, intrínseca aos sistemas sociais, levanta uma alta carga de variação e imprevisibilidade na sociedade, o que faz que nem sempre as expectativas 
sejam satisfatoriamente mantidas: quando uma comunicação é produzida por Ego, este espera que Alter reaja da forma x (expectativa), porém Alter reage da forma y (contingência); Alter espera que Ego lide com sua reação da forma z (expectativa), mas Ego externa uma reação $n$ diversa da esperada (contingência) (I).

A função que as expectativas cumprem é a de orientar estavelmente a comunicação diante de toda essa complexidade e contingência. Quando as expectativas se condensam, é possível selecionar a partir de um âmbito global de possibilidade e, por consequência, manter a complexidade reduzida, bem como utilizar as próprias generalizações de maneira que ultrapassem os limites da situação específica. Essa condensação permite uma estruturação da complexidade, portanto, conhecer a realidade externa na ausência de possibilidade de acesso direto a ela (CORSI; ESPOSITO; BARALDI, 1996, p. 80).

Em um contexto de relações entre Ego e Alter, isso significa reconhecer o outro como variável e imprevisível e introduzir nas próprias expectativas uma margem de variação e imprevisão na realidade que se espera (II). Trata-se de antecipar as antecipações do outro: à medida que Ego compreende a orientação de Alter, pode orientar o seu próprio atuar - e só assim a realização da comunicação é possível, pois, sem a possibilidade de esperar a expectativa do outro, não seria possível orientar as próprias ações e continuar a comunicação (III).

As expectativas das expectativas no interior dos sistemas sociais são suas estruturas, permitindo assim que se coordenem as seletividades da outra parte na comunicação ${ }^{9}$.

Estruturas (de expectativas) nada mais são que o âmbito de restrições das relações admitidas nos sistemas (LUHMANN, 1991, p. 384; 2016a, p. 319). Refere-se à interconectividade recursiva das operações (comunicações) que são utilizadas no sistema (LUHMANN, 2013, p. 244) - ou seja, é a maneira pela qual uma comunicação encontra a próxima mais adequada para dar continuidade à anterior ${ }^{10}$, visando construir um sentido.

9 Primeiramente, é preciso selecionar um tema, uma informação, sobre a qual se quer comunicar; sabendo isso, pode-se escolher determinado comportamento para dar conhecimento; e, por fim, é preciso compreender que a informação e o ato de dar a conhecer são duas coisas distintas, possibilitando assim que se possa selecionar um próximo comportamento. Essa é a recursividade da comunicação: a participação de Ego e Alter em cada comunicação (TONET, 2019, p. 62)

10 "[...] sistemas producen estructuras mediante sus propias operaciones, las que a su vez suponen que las estructuras dirigen el establecimiento de operaciones conectivas" (MANSILLA; NAFARRATE, 2008, p. 326). 
Expectativas reflexivas podem decepcionar, motivo pelo qual a sociedade moderna desenvolve dois tipos (contrários) de reação, duas estratégias para lidar com desapontamentos de expectativas, para a manutenção de sua auto-organização e autoprodução:

Mesmo quando os desapontamentos se tornam visíveis e têm que ser inseridos na visão de realidade como objeto de experimentação, ainda existe a alternativa de modificação da expectativa desapontada, adaptando-a à realidade decepcionante, ou então sustentar a expectativa, e seguir a vida protestando contra a realidade decepcionante. Dependendo de qual dessas orientações predomina, podemos falar de expectativas cognitivas ou normativas (LUHMANN, 1983, p. 55- 56, grifos no original).

Quando se fala em expectativas cognitivas, reporta-se à disposição de aprender quando se sofre um desapontamento, adaptando-se à realidade. Já as expectativas normativas não são abandonadas em face das decepções - quer dizer, sabe-se que existe a possibilidade de se desapontar (pois o mundo é complexo e contingente), mas de antemão isso é tido como irrelevante para a expectativa (LUHMANN, 1983, p. 56) ${ }^{11}$.

De forma geral: como o sistema não pode operar fora de suas estruturas, toda complexidade indeterminada (realidade externa) é conhecida a partir da condensação de expectativas, ou seja, pela introdução de variabilidade e imprevisibilidade nas próprias expectativas (expectativas de expectativas, expectativas reflexivas). Essa margem de incerteza é processada internamente como decepção, razão pela qual se adota uma das estratégias de assimilação de desapontamento de expectativas mencionadas antes, que são funcionalmente equivalentes, a fim de se adiantar e orientar o seu próprio atuar, limitando as relações admitidas nas comunicações, visando construir um sentido específico.

\section{Conclusão}

O presente trabalho se propôs a apresentar três conceitos-chave para a compreensão da sociologia do direito (Rechtssoziologie) de Niklas Luhmann, com uma construção

\footnotetext{
11 “A norma se mantém condensada mediante as sequências operativas da prática que a antecedeu e a sucederá [...]. Isso não exclui de maneira concreta o comportamento ilícito no interior do sistema jurídico nem as decisões ilegais dos tribunais. Entretanto, assim, a caracterização 'contrária à legalidade' se mantém possível, o que tem consequências para as outras operações do sistema - seja na forma da suspensão de uma decisão ainda desprovida de força jurídica, seja na forma de não consideração, por orientação posterior, das decisões precedentes”(LUHMANN, 2016b, p. 108).
} 
linguística que busca reduzir a complexidade do arcabouço teórico, mas não de forma simplória, haja vista que o objetivo é permitir que acadêmicos e pesquisadores que nunca tiveram contato com a teoria dos sistemas agora possam fazê-lo, de maneira que não se deparem abruptamente com a complexa linguagem e diversos elementos que requerem maior conhecimento teórico.

Assim sendo, o principal resultado observado é a listagem e explicação, de forma pontual, de conceitos-chave do pensamento jus-sociológico luhmanniano, mas que também podem ser utilizados pelo leitor para seguir em outros escritos.

Destaca-se, no entanto, que o presente estudo é limitado a apresentar e explicar as conceituações de três categorias concernentes à sociologia do direito luhmanniana, portanto anterior à chamada "virada autopoiética”. Em razão disso, aprofundamentos sobre autopoiese, autorreferência/heterorreferência, meios de comunicação simbolicamente generalizados, observação de segunda ordem, entre outros, foram evitados para não fugir à proposta e causar confusão ao leitor.

Por último, o objetivo foi satisfatoriamente atingido, porém com a ressalva de que foi necessário introduzir o par conceitual código binário/programação para complementar a explicação sobre positividade do direito. Tais categorias só vão ser posteriormente incorporadas por Luhmann após a "virada autopoiética", haja vista o contato com a cibernética de segunda ordem (Heinz von Foerster) e a teoria da autopoiese (Humberto Maturana e Francisco Varela).

\section{REFERÊNCIAS}

ALCOVER, P. G. El derecho en la teoria de la sociedad de Niklas Luhmann. Barcelona: José María Bosch Editor, 1993.

CORSI, G.; ESPOSITO, E.; BARALDI, C. GLU: glosario sobre la teoría social de Niklas Luhmann. Traducción Miguel Romero Pérez, Carlos Villalobos. Dirección Javier Torres Nafarrate. Ciudad de México: Universidad Iberoamericana, 1996.

DUTRA, R. O problema da desigualdade social na teoria da sociedade de Niklas Luhmann. Caderno CRH, v. 27, p. 547-561, 2014.

DUTRA, R. Diferenciação funcional e a sociologia da modernidade brasileira. Política \& Sociedade, v. 15, p. 77-109, 2016.

DUTRA, R. Por uma sociologia sistêmica pós-colonial das diferenças no interior da sociedade mundial. Sociedade e Estado, v. 35, p. 259-286, 2020.

EXPECTATION. In. WEBSTER'S new encyclopedic dictionary. New York: Black Dog \& Leventhal Publishers, 1995. 
HOFSTADTER, D. R. Gödel, Escher, Bach: um entrelaçamento de gênios brilhantes. Tradução José Viegas Filho. Brasília, DF: Editora Universidade de Brasília, 2001.

IZUZQUIZA, I. La sociedade sin hombres: Niklas Luhmann o la teoria como escandalo. 2. ed. Rubí, Barcelona: Anthropos Editorial, 2008.

LUHMANN, N. Differentiation of society. The Canadian Journal of Sociology, v. 2, n. 1, p. 29-53, 1977.

LUHMANN, N. Sociologia do direito I. Tradução Gustavo Bayer. Rio de Janeiro: Edições Tempo Brasileiro, 1983.

LUHMANN, N. Sociologia do direito II. Tradução Gustavo Bayer. Rio de Janeiro: Edições Tempo Brasileiro, 1985.

LUHMANN, N. Ecological communication. Translation John Bedznarz Jr. Chicago: University of Chicago Press, 1989.

LUHMANN, N. Essays on self-reference. New York: Columbia University Press, 1990a.

LUHMANN, N. Verfassung als evolutionäre Errungenschaft. Rechthistorisches Journal, v. 9, p. 176-220, 1990b.

LUHMANN, N. Soziale systeme: Grundriss einer algemeinen Theorie. 4. aufl. Frankfurt am Main: Suhrkamp, 1991.

LUHMANN, N. Deconstruction as second-order observing. New Literary History, v. 24, n. 4, p. 763-782, 1993a.

LUHMANN, N. Das Recht der Gesellschaft. Frankfurt am Maim: Suhrkamp, 1993b.

LUHMANN, N. Kausalität im Süden. Soziale Systeme, v. 1, n. 1, p. 7-28, 1995.

LUHMANN, N. Sobre os fundamentos teórico-sistêmicos da teoria da sociedade. In: NEVES, C. B.; SAMIOS, E. M. B. (coord.). Niklas Luhmann: a nova teoria dos sistemas. Porto Alegre: Editora UFRGS, ICBA, 1997.

LUHMANN, N. Complejidad y modernidad: de la unidad a la diferencia. Traducción Josetxa Berian y José Maria García Blanco. Madrid: Editorial Trotta, 1998.

LUHMANN, N. Organización y decisión. Wiesbaden: Westdeutscher Verlag GmbH, 2000.

LUHMANN, N. Ciência incompreensível: problemas de uma linguagem própria à teoria. Novos Estudos Cebrap, n. 63, p. 51-59, 2002.

LUHMANN, N. La sociedad de la sociedad. Traducción de Javier Torres Nafarrate. Ciudad de México: Editorial Herder, 2006.

LUHMANN, N. Introduction to Systems Theory. Translated by Peter Gilgen. Malden, USA: Polity Press, 2013.

LUHMANN, N. Sistemas sociais: esboço de uma teoria geral. Tradução Antonio C. Luz Costa, Roberto Dutra Torres Junior e Marco Antonio dos Santos Casanova. Petrópolis: Vozes, $2016 \mathrm{.}$.

LUHMANN, N. O direito da sociedade. Tradução Saulo Krieger. São Paulo: Martins Fontes, 2016b. 
MANSILLA, D. R.; NAFARRATE, J. T. Introducción a la teoria de la sociedad de Niklas Luhmann. Ciudad de México: Heder, 2008.

MATURANA, H.; VARELA, F. De máquinas y seres vivos: autopoiesis, la organización de lo vivo. Buenos Aires: Lumen, 2003.

NEVES, M. Entre Têmis e Leviatã: uma relação difícil: o Estado Democrático de Direito a partir e além de Luhmann e Habermas. 3. ed. São Paulo: WMF Martins Fontes, 2012.

NEVES, M. Constituição e direito na modernidade periférica: uma abordagem teórica e uma interpretação do caso brasileiro. São Paulo: WMF Martins Fontes, 2018.

ROCHA, L. S.; SCHWARTZ, G.; CLAM, J. Introdução à teoria do sistema autopoiético do direito. 2. ed. rev. e ampl. Porto Alegre: Livraria do Advogado, 2013.

RODRIGUES, L. P.; NEVES, F. M. A sociologia de Niklas Luhmann. Petrópolis, RJ: Vozes, 2017.

SCHWARTZ, G.A.D. As teses radicais de Luhmann. Revista de Estudos Constitucionais, Hermenêutica e Teoria do Direito (RECHT D), v. 6 (1): 111-114, janeiro-junho, 2014. doi: 10.4013/rechtd.2014.61.11.

SOUZA, M. F. N. de; TONET, F. A insuficiência de diferenciação funcional observada a partir da crise no cenário brasileiro. RBSD - Revista Brasileira de Sociologia do Direito, v. 5, n. 3, p. 180-202, set./dez. 2018. doi: 10.21910/rbsd.v5n3.2018.266.

STICHWEH, R. An diesem Imperativ kann die Politik scheitern. Frankfurter Allgemeine Zeitung, 7 Apr. 2020. Disponível em: https://www.faz.net/aktuell/feuilleton/debatten/an-diesem-imperativ-kann-die-politik-scheitern-16714610.html. Acesso em: 25 jun. 2020.

STICHWEH, R. Elementos-chave de uma teoria da sociedade mundial. Sociedade e Estado, v. 33, n. 2, p. 389-406, maio/ago. 2018. doi: 10.1590/s0102-699220183302005.

STOURZH, G. Constitution: changing meanings of the term from the early seventeenth to the late eighteenth century. In: STOURZH, G. From Viena to Chicago and back: essays on intellectual history and political thought in Europe and America. Chicago: University of Chicago Press, 2007.

TONET, F. Entre Cila e Caríbdis: o árduo caminho do constitucionalismo sistêmico. São Leopoldo, RS: Ed. UNISINOS, 2019. 